\title{
Effects of iron supplement and exercise intensities on the levels of blood hemoglobin among Jimma University male soccer players
}

\author{
Biruk AMARE1 , Molla DEYOU ${ }^{2}$, Sirak H/MARIAM ${ }^{3}$ \\ ${ }^{1}$ Department of Sport Sciences, Jimma University, Jimma Ethiopia. \\ 2 Department of Sport Sciences, Haramaya University, Haramaya Ethiopia. \\ ${ }^{3}$ Director of Ethiopian sport academy, Addis Ababa Ethiopia. \\ Address correspondence to Biruk Amare, amarebruk@gmail.com
}

\begin{abstract}
This study was aimed to examine the effects of Iron Supplement and Exercise Intensities on the Levels of Blood Hemoglobin among Jimma University Male Soccer Players. The subjects of this study were twenty male soccer players (ten players in each group) and they were purposively selected and randomly assigned in each group. Anthropometric (age, height, weight and body mass index), physiological (resting heart rate and blood pressure), endurance performance (12 min run and Bruce incremental test) and hematological (hemoglobin and red blood cell tests) variables were tested by digital scale in meter, digital balanced beam scale in kilogram, and body mass index was calculated, Sphygmomanometer, stop watch and humacount hematology analyzer. The analyses were carried out by the descriptive statistical analysis included mean and standard deviation, using SPSS version 16.0 software with a p-value $<0.05 .5 \mathrm{ml}$ of blood sample were collected before, during and after supplying iron with folic acid in the 12 weeks of the study period. Therefore, both in high and moderate intensity training statistically significant mean difference were observed in RHR, SBP, DBP, Cooper test, HB and RBC at $(\mathrm{p}<0.05)$ The mean RBC difference of high and moderate intensity group was $0.98 \mathrm{ml} / \mathrm{cm}^{3}(22.99 \%)$ and $0.75 \mathrm{ml} / \mathrm{cm}^{3}(17.94 \%)$ respectively before and after supplementation and endurance training. The mean HB difference of high and moderate intensity group was $3.35 \mathrm{~g} / \mathrm{dl}(23.29 \%)$ and by $2.05 \mathrm{~g} / \mathrm{dl}(14.36 \%)$ respectively before and after supplementation and endurance training. This study showed that iron supplementation increased hemoglobin level of soccer players in high intensity and moderate intensity endurance training.
\end{abstract}

Keywords: Hemoglobin, iron supplement, red blood cell, soccer player.

\section{INTRODUCTION}

Good performance in soccer consists of many factors, including excellence in games skills, cognitive abilities to make correct decisions within the game, moderate to high aerobic and anaerobic power (1). Endurance performance at reduced exercise intensities, however, is more closely related to tissue iron concentrations because of the strong association between the ability to maintain prolonged submaximal exercise and the activity of iron-dependent oxidative enzymes.

Several studies have examined the effect of iron supplementation on iron stores and on parameters characterizing changes in aerobic capacity or physical fitness $(2,4,7-11,14,16,18,19)$. As far as individuals with iron deficiency anemia are concerned, there is no question as to the benefit of iron-containing medications, because even mild anemia decreases the capacity for performance of physical exercise substantially $(6,20)$.

In general, a small but significant increase in serum ferritin levels is observed following iron supplementation in most studies enrolling nonanemic athletes. Using the approximation that a $1 \mathrm{~g} / \mathrm{L}$ increase in serum ferritin is equivalent to $8 \mathrm{mg}$ of storage iron (23), iron supplementation added a mean of between 88 to $240 \mathrm{mg}$ of iron to body stores $(2,4,7-11,13-16,18,19)$.

Some investigators also identified objective signs of improved fitness such as increased $\mathrm{VO}_{2 \max }$ $(9,10)$, longer endurance time to exhaustion $(9,19)$, and decreased blood lactate levels (9) and subjective parameters, for example increased training motivation $(13,18)$. However, it is possible that some of the athletes were slightly anemic at study entry and that the positive effects noted in these studies 
$(9,10,19)$ were simply caused by the normalization of hemoglobin concentrations.

The physiological roles of minerals are importance to the athletes muscle contraction, normal heart rhythm, nerve impulse conduction, oxygen transport, oxidative phosphorylation, enzyme activation, immune functions, antioxidant activity, bone health, and acid-base balance of the blood (22).

In elite athletes daily iron losses are often increased, but this is usually compensated by enhanced absorption of dietary iron (21). Thus, we hypothesized that iron supplement and exercise intensities could have positive effects on increasing hemoglobin concentration which is the protein in red blood cells that carries oxygen to the working tissues. Therefore, the purpose of this study was to examine the effects of iron supplement and exercise intensities on the levels of blood hemoglobin.

\section{METHODOLOGY}

\section{Study Area}

The study was conducted in Jimma zone, Jimma University, main campus in Jimma town, located $350 \mathrm{~km}$ in south-west of Addis Ababa.

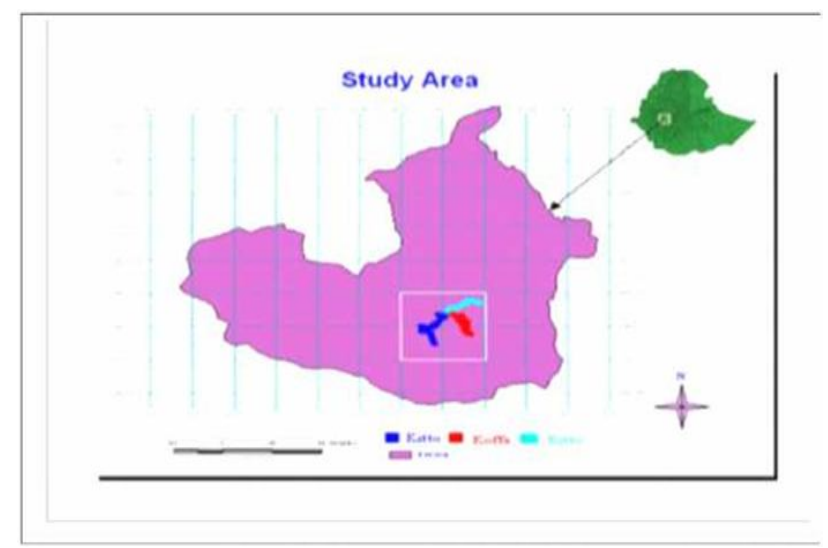

Figure 1. Map of the study area

\section{Study Design}

The researcher used longitudinal experimental research design because participants are tested than one test and trained for 12 weeks. Therefore, the data were collected from Jimma University Male Soccer Players.

\section{Subjects}

Twenty male intermediate players were purposively selected who took part in national higher governmental institutions sport festival was taken for this study. Then after, the selected subjects were evaluated the baseline iron and randomly and equally categorized in to high and moderate intensity groups before iron supplement and endurance trainings.

Participants were free of risk factors associated with cardiovascular, pulmonary or metabolic disease, deemed safe to begin physical activity, and were not engaged in other regular training program. Other exclusion criteria included medication usage and smoking. The experimental procedures and potential risks were explained prior to the study, and all participants signed written, informed consent.

\section{Supplementation and Exercise Protocol}

Both groups were supplied $3 \mathrm{mg}$ of iron with folic acid in tablet form three days per week for 12 weeks of the study period. After they supplied iron with folic acid both high and moderate intensity group were perform endurance exercise. The endurance training programs were long aerobic run, speed $\mathrm{VO}_{2}$ intervals, tempo run and strength efforts.

The exercises were supervised and the intensities were verified by checking the participants' maximum heart rate during training.

The high intensity training group was performed high intensity $(70 \%-85 \%$ HR max) endurance training at Monday, Wednesday and Friday and the moderate intensity training group was also perform moderate intensity $(50 \%-70 \% \mathrm{HR}$ max) endurance training at Tuesday, Thursday and Saturday. They were perform 6:00 Am to 7:00 Am throughout the study because to minimize the risk of inconvenient time of the players.

\section{Data Quality Control}

To ensure the data quality, the researcher and Jimma University specialized hospital certified laboratory technician was conduct all the laboratory test procedures including collection and handling of materials carry out in accordance with standard protocols. The researcher and laboratory technician was check the expired date of all the reagents and keep them from contamination when using and store in favorable temperature. To ensure general safety, disposable gloves were worn out and universal precautions follow at all times. Sample collection was carried out using sterile and disposable materials.

\section{Statistical Analysis}

Descriptive statistics included mean and standard deviation was used to analyze the data and 
in order to summarize hematological changes and physiological as well as fitness and performance status. Differences in mean values between 2 groups were analyzed using SPSS statistical software version 16.0. A p-value $<0.05$ was considered to be statistically significant.

\section{Ethical Issues}

The study was conducted under the auspices of Haramaya University rules, policies and code of conduct governing research activities and ethical issues and also obtained approval from the Institutional Research Ethics Review Committee (IRERC) of Haramaya University College of Public Health and Medical Science, stationed at Harar campus.

\section{RESULTS AND DISCUSSION}

\section{Hematological Test Results and Discussion}

The mean RBC difference of high and moderate intensity group was $0.98 \mathrm{ml} / \mathrm{cm}^{3}(22.99 \%)$ and 0.75 $\mathrm{ml} / \mathrm{cm}^{3}(17.94 \%)$ respectively before and after iron supplementation and endurance training. The mean HB difference of high and moderate intensity group was $3.35 \mathrm{~g} / \mathrm{dl}(23.29 \%)$ and by $2.05 \mathrm{~g} / \mathrm{dl}(14.36 \%)$ respectively before and after iron supplementation and endurance training. The soccer players showed significant increment of RBC and hemoglobin.

Endurance athletes with normal hemoglobin status who attempt to increase their red blood cells (RBC) and hemoglobin levels may benefit from iron supplementation (12). Iron absorption is the main mechanism through which iron balance is maintained. Iron plays a critical role in oxygen transport as it is necessary for the formation of $\mathrm{Hb}$, the oxygen transport protein that is critical for aerobic capacity.

\section{Physiological and Performance Efficiency Test Result and Discussion}

Table 3 showed that significance mean differences in RHR (resting heart rate) within each test between the groups. The mean RHR distribution of high intensity group was decreased by $3.70 \mathrm{~b} / \mathrm{min}$ $(6.07 \%)$. However, the mean RHR distribution of moderate intensity group was decreased by 2.80 $\mathrm{b} / \mathrm{min}(4.51 \%)$. In this context, high intensity group was revealed better mean RHR decrement.

And as indicated in Table 3 blood pressure (Sbp (systolic blood pressure) and Dbp (diastolic blood pressure)) mean difference was decreased by 7.5 $\mathrm{mmHg}(6.66 \%) \mathrm{Sbp}$ and $9 \mathrm{mmHg}$ (12\%) Dbp in high intensity group and also at moderate intensity group mean difference was decreased by $3.5 \mathrm{mmHg}$ (3.09\%) Sbp and $5.5 \mathrm{mmHg}$ (7.14\%) Dbp. Here also high intensity group was revealed better mean decrement in both systolic blood pressure and diastolic blood pressure.

Exercise and/or physical activity is characterized by a substantial increase in oxygen needs. Iron is an essential factor for the formation of $\mathrm{Hb}$, the protein responsible for oxygen transport from the respiratory organs to the peripheral tissues (1). Increases in central O2 delivery (cardiac output) and peripheral $\mathrm{O}_{2}$ uptake (arteriovenous oxygen difference) contribute to training induced improvements in cardiorespiratory fitness (3).

Table 1. Characteristics of the study subjects (Mean \pm SD).

\begin{tabular}{lccc}
\hline & \multicolumn{2}{c}{ High Intensity $(\mathrm{N}=10)$} & Moderate Intensity $(\mathrm{N}=10)$ \\
\cline { 2 - 4 } & Before Supplement & After Supplement & Before Supplement \\
\hline Age (years) & $22.1 \pm 0.73$ & $22.1 \pm 0.73$ & $23 \pm 1.24$ \\
Height $(\mathrm{m})$ & $1.78 \pm 0.04$ & $1.78 \pm 0.04$ & $1.74 \pm 0.06$ \\
Weight $(\mathrm{Kg})$ & $59.6 \pm 5.7$ & $60.4 \pm 6.39$ & $62.2 \pm 7.88$ \\
BMI $\left(\mathrm{Kg} / \mathrm{m}^{2}\right)$ & $18.64 \pm 1.25$ & $18.71 \pm 1.33$ & $20.28 \pm 1.36$
\end{tabular}

Mean \pm SD in the same columns in each parameter are not significantly different $(\mathrm{p}<0.05), \mathrm{BMI}\left(\mathrm{kg} / \mathrm{m}^{2}\right)=$ Body mass index.

Table 2. Mean value of hematological test of high and moderate intensity group of soccer players before and after iron supplementation.

\begin{tabular}{lccc}
\hline & \multicolumn{2}{c}{ High Intensity } & Moderate Intensity \\
\cline { 2 - 4 } Treatments & RBC & Hb & RBC \\
& & & \\
Before supplement & $4.28 \pm 0.132$ & $14.38 \pm 0.209$ & $4.18 \pm 0.135$ \\
After supplement & $5.26 \pm 0.132$ & $17.73 \pm 0.377$ & $4.93 \pm 0.255$ \\
Mean diff. & $-0.9840^{*}$ & $-3.350^{*}$ & $-0.750^{*}$ \\
Sig. & 0.000 & 0.000 & 0.000 \\
\end{tabular}

Means \pm in the same column in each parameter with different ${ }^{*}$ superscripts are significantly different $(\mathrm{p}<0.05) \mathrm{RBC}=$ red blood cell and $\mathrm{HB}=$ hemoglobin. Turk J Spart Exe 2014; I6(I): 90-94 
Table 3. Mean effects of physiological and performance efficiency test of high and moderate intensity group of the JU soccer players.

\begin{tabular}{|c|c|c|c|c|c|c|c|c|c|c|}
\hline \multirow[t]{2}{*}{ Treatments } & \multicolumn{5}{|c|}{ High Intensity group } & \multicolumn{5}{|c|}{ Moderate Intensity group } \\
\hline & RHR & Sbp & Dbp & Cooper & Bruce & RHR & Sbp & Dbp & Cooper & Bruce \\
\hline $\begin{array}{l}\text { Before } \\
\text { supplement }\end{array}$ & $60.90 \pm 3.54$ & $112.50 \pm 5.401$ & $75.00 \pm 5.27$ & $2740 \pm 134.99$ & $7.20 \pm 0.63$ & $62.00 \pm 2.82$ & $113.00 \pm 4.83$ & $77.00 \pm 4.83$ & $2620 \pm 187.38$ & $6.80 \pm 1.39$ \\
\hline $\begin{array}{l}\text { After } \\
\text { supplement }\end{array}$ & $57.20 \pm 3.29$ & $105.00 \pm 4.08$ & $66.00 \pm 3.94$ & $3320 \pm 257.33$ & $9.40 \pm 0.84$ & $59.20 \pm 3.15$ & $109.50 \pm 1.58$ & $71.50 \pm 3.37$ & $2860 \pm 250.33$ & $8.00 \pm 1.33$ \\
\hline Mean diff. & $3.70^{*}$ & $7.50^{*}$ & $9.00^{*}$ & $-580.00^{*}$ & $-2.20^{*}$ & $2.80^{*}$ & $3.50^{*}$ & $5.50^{*}$ & $-240.00^{*}$ & -1.20 \\
\hline Sig. & 0.021 & 0.000 & 0.000 & 0.000 & 0.000 & 0.050 & 0.032 & 0.012 & 0.025 & 0.058 \\
\hline
\end{tabular}
$(\mathrm{mmHg})=$ systolic blood pressure.

And also as indicated in table 3 the mean value of Cooper test in high intensity and moderate intensity group was increased to $580 \mathrm{~m}(21.16 \%)$ and $240 \mathrm{~m}(9.16 \%)$ respectively. This result indicates that effective performance have been observed in high intensity group than moderate intensity group.

The improvement of iron status due to iron supplementation has been accompanied by an improvement in endurance capacity $(5,19)$. However, in Bruce incremental treadmill test no improvements have been observed in moderate intensity group.

High intensity group develop better RBC and $\mathrm{Hb}$ level than moderate intensity endurance group of Jimma University soccer players. Iron supplementation to soccer players with high intensity endurance exercise is necessary to RCB and $\mathrm{Hb}$ concentration increment. High intensity group highly improved physiological (RHR, Sbp and Dbp) and endurance performance efficiencies than moderate intensity endurance group of $\mathrm{JU}$ soccer players. Iron is essential for endurance exercise for the formation of hemoglobin and oxygen carrying capacity.

By considering the major findings and conclusions of the study, it is important to state the following points as a recommendation to investigate more on effects of iron supplementation hematological change, physiological and performance efficiency. It is highly expected from sport nutritionists, sport professionals and related fields to guide and educate on the importance and value of iron supplementation with high intensity endurance exercise on physiological changes and performance efficiency. To be more beneficial in all dimensions (physiological change, performance efficiency and hematological changes) soccer players should use iron supplementation with high intensity endurance exercise additional to their meal. Further research has to be done on the role of iron for the improvement of soccer player's physiological, performance efficiency and hematological changes.

\section{REFERENCES}

1. Beard JL. Iron biology in immune function, muscle metabolism and neuronal functioning. J Nutr, 2001; 131: 2S-2.

2. Dressendorfer RH, Keen CL, Wade CE, Claybaugh JR, Timmis GC. Development of runner's anemia during a 20day road race: effect of iron supplements. Int J Sports Med, $1991 ; 12$ : 332-6.

3. Driskell J. Vitamins and trace elements in sports nutrition. New York (NY): CRC/Taylor and Francis. 2006, pp. 323-31.

4. Fogelholm M, Jaakkola L, Lampisjaervi T. Effects of iron supplementation in female athletes with low serum ferritin concentration. Int J Sports Med, 1992; 13: 158-62.

5. Friedmann B, Weller E, Mairbaurl H, Bartsch P. Effects of iron repletion on blood volume and performance capacity in young athletes. Medicine and Science in Sports and Exercise, 2001; 33(5): 741-746.

6. Gardner GW, Edgerton VR, Barnard RJ, Bernauer EM. Cardiorespiratory, hematological and physical performance responses of anemic subjects to iron treatment. Am J Clin Nutr, $1975 ; 28$ : 982-8.

7. Karamizrak SO, Islegen C, Varol SR, Taşkiran Y, Yaman C, Mutaf I, Akgün N. Evaluation of iron metabolism indices and their relation with physical work capacity in athletes. Br J Sports Med, 1996; 30: 15-9.

8. Klingshirn LA, Pate RR, Bourque SP, Davis JM, Sargent RG. Effect of iron sup- plementation on endurance capacity in iron-depleted female runners. Med Sci Sports Exerc, 1992; 24: 819-24.

9. LaManca JJ, Haymes EM. Effects of iron repletion on VO2max, endurance, and blood lactate in women. Med Sci Sports Exerc, 1993; 25: 1386-92.

10. Magazanik A, Weinstein $Y$, Abarbanel J, Lewinski U, Shapiro Y, Inbar O, Epstein S. Effect of an iron supplement on body iron status and aerobic capacity of young training women. Eur J Appl Physiol, 1991; 62: 317-23.

11. Matter M, Stittfall T, Graves J, Myburgh K, Adams B, Jacobs $P$, Noakes TD. The effect of iron and folate therapy on maximal exercise performance in female marathon runners with iron \& folate deficiency. Clin Sci, 1987; 72: 415-2.

12. Williams MH. Dietary Supplements and Sports Performance: Minerals. Journal of the Int Society of Sports Nutrition, 2005; 2(1): 43- 49 . 
13. Nachtigall D, Nielsen P, Fischer R, Engelhardt R, Gabbe EE. Iron deficiency in distance runners: a reinvestigation using 59Fe-labelling and non-invasive liver iron quantification. Int J Sports Med, 1996; 17: 473-9.

14. Newhouse IJ, Clement DB, Taunton JE, McKenzie DC. The effects of prelatent/latent iron deficiency on physical work capacity. Med Sci Sports Exerc, 1989; 21: 263-8.

15. Pattini A, Schena F. Effects of training and iron supplementation on iron status of cross-country skiers. J Sports Med Phys Fitness. 1990; 30 (4): 347-53.

16. Powell PD, Tucker A. Iron supplementation and running performance in female cross-country runners. Int J Sports Med, 1991; 12: 462-7.

17. Reilly T, Bangsbo J, Franks A. Anthropometric \& physiological predispositions for elite soccer. Journal of Sports Science, 2000; 18: 669-83.

18. Risser WL, Lee EJ, Poindexter HBW, West MS, Pivarnik JM, Risser JM, Hickson JF. Iron deficiency in female athletes: its prevalence and impact on performance. Med Sci Sports Exerc, 1988; 20: 116-21.

19. Rowland TW, Deisroth MB, Green GM, Kelleher JF. The effect of iron therapy on the exercise capacity of nonanemic irondeficient adolescent runners. American Journal of Diseases of Children; 1988; 142(2): 165-169.

20. Schoene RB, Escourrou P, Robertson HT, Nilson KL, Parsons JR, Smith NJ. Iron repletion decreases maximal exercise lactate concentrations in female athletes with minimal irondeficiency anemia. J Lab Clin Med, 1983; 102: 306-12.

21. Scobie BA. Recurrent gut bleeding in five long-distance runners. N Z Med J, 1985; 98(790): 966.

22. Speich M, Pineau A, Ballereau F. Minerals, trace elements and related biological variables in athletes and during physical activity. Clinical Chemistry Acta. Research Letter. 2001; 28: $311-314$.

23. Walters GO, Miller FM, Woorwood M. Serum ferritin concentration and iron stores in normal subjects. J Clin Pathol, 1973; 26: 770-2. 